\title{
An investigation of the photo-reactive and unreactive polymorphs of $o$-ethoxy cinnamic acid and of its photodimer
}

\author{
R SRINIVASA GOPALAN and G U KULKARNI* \\ Chemistry and Physics of Materials Unit, Jawaharlal Nehru Centre for \\ Advanced Scientific Research, Jakkur PO, Bangalore 560 064, India \\ e-mail: kulkarni@jncasr.ac.in
}

MS received 29 November 2000

\begin{abstract}
Detailed X-ray crystallographic investigation of the reactive $\alpha$ - and the unreactive $\gamma$-polymorphs of $o$-ethoxy cinnamic acid has been carried out along with that of the photodimer, $\alpha$-truxillic acid. The molecule is quite planar in the $\alpha$-form, but in the $\gamma$-form, the side groups deviate significantly from the plane of the benzene ring. The carboxylic groups form normal cyclic hydrogen bonds in the $\alpha$-form and near-symmetric hydrogen bonds in the $\gamma$-form. The infrared spectrum of the $\alpha$-form shows the characteristic features of the cyclic dimer, but that of the $\gamma$-form is entirely different, marked by the absence of the $\mathrm{O}-\mathrm{H}$ stretching band in the $3000 \mathrm{~cm}^{-1}$ region. Charge density analysis throws some light on the structure and reactivity of the molecule in the two forms. The near-symmetric hydrogen bond in the $\gamma$-form is ionic and appears to restrict conjugation by way of distorting the molecule. This unusual feature keeps the cinnamoyl double bonds away from each other, rendering it photochemically unreactive. In the $\alpha$-form, however, the double bonds have a closer approach. The cyclobutyl ring of the photodimer consists of weak single bonds, with the new pair being slightly longer.
\end{abstract}

Keywords. Photoreactivity; polymorphism; ethoxy cinnamic acid; electronic charge density; X-ray structure.

\section{Introduction}

Photochemical dimerization in cinnamic acid and its derivatives, first investigated by Cohen et $a l^{1}$, is a classic in organic solid state chemistry. They established the general requisites for this $(2+2)$ cycloaddition reaction to occur in the solid state. An important requirement for the reaction is the near parallel orientation of the reactive double bonds and a relatively short distance $(3 \cdot 7-4.2 \AA$ ) between them, the approach involving small displacive or angular motions. The cinnamic acids generally exist in polymorphic forms. The reactive $\alpha$ - and $\beta$-forms undergo photochemical dimerization to yield the corresponding symmetry-related $\alpha$-truxillic acid and the $\beta$-truxinic acid respectively. The $\gamma$-form, where it exists, is photostable. Based on a single crystal-single crystal Xray diffraction study of the photodimerization of the $\alpha$-form of trans-cinnamic acid, Enkelmann et $a l^{2}$ found that the double bonds of the incipient cyclobutane ring show large displacements, while the phenyl and the carboxylic groups remain essentially in

\footnotetext{
*For correspondence
} 
place. It was our desire to carry out thorough crystallographic investigation of both the reactive and the unreactive forms of cinnamic acid, to see how the structural features relate to the reactivity. For this purpose, we have determined the structures of the $\alpha-$ and $\gamma$-forms of $o$-ethoxy cinnamic acid as well as of the photodimer of the $\alpha$-form. The present study shows how the intermolecular hydrogen bond is significantly different in the $\alpha$ - and the $\gamma$-forms and that in the latter it is primarily responsible for rendering the molecule non-planar and photochemically unreactive.

Charge density analysis is useful in understanding intra- and intermolecular bonding as well as properties and reactivities of molecular crystals ${ }^{3}$. Ortmann et al ${ }^{4}$ applied this method to study a photoreactive pyrone molecule in comparison with an isoelectronic photostable oxazinone. Madsen et al ${ }^{5}$ have studied hydrogen bonds with very short $\mathrm{O} \cdots \mathrm{O}$ contacts. A charge density study of $p$-nitrophenol has established interesting differences between two polymorphs of this compound, one of which is photochemically active ${ }^{6}$. In this paper, we report charge-density analysis of the reactive $\alpha$ - and the unreactive $\gamma$-forms of $o$-ethoxy cinnamic acid. We observe that the charge concentrations in various regions are more even in the $\alpha$-form compared to those in the $\gamma$-form. There are significant differences in the hydrogen bond regions as well.

\section{Experimental}

$o$-Ethoxy cinnamic acid was prepared by the Knoevenagel reaction of $o$-ethoxy benzaldehyde and malonic acid in pyridine containing traces of bipyridine ${ }^{7}$. The $\alpha-$ form was obtained by the slow evaporation of a concentrated solution in ethyl acetate while slow cooling of a solution in ethanol-water mixture gave the $\gamma$-form. The process of cooling from $75^{\circ} \mathrm{C}$ to room temperature was carried out over a period of three days. Unlike trans-cinnamic acid $^{2}$, the $o$-ethoxy cinnamic acid does not favour single crystal-single crystal photodimerization. In order to obtain the photodimer, 2,2'-diethoxy $\alpha$-truxillic acid (trans-2,4-bis(2-ethoxyphenyl)-trans-1,3cyclobutane dicarboxylic acid), crystals of the $\alpha$-form were irradiated at room temperature using a mercury vapour lamp. After about an hour, the resulting compound was cleaned with copious amounts of ether, when the unreacted parent material went into solution while the product remained insoluble. This process was carried out a few times in order to remove all traces of the parent compound. The photodimer was dissolved in hot glacial acetic acid and filtered before crystallizing it under slow evaporation.

High quality crystals of $\alpha$ - and $\gamma$-forms of the $o$-ethoxy cinnamic acid and of the dimer were chosen after examination under an optical microscope. X-ray diffraction intensities were measured by $\omega$ scans using a Siemens three-circle diffractometer attached to a CCD area detector and a graphite monochromator for the MoK $\alpha$ radiation $(50 \mathrm{kV}, 40 \mathrm{~mA})$. The crystals were cooled to $130 \mathrm{~K}$ on the diffractometer using a stream of cold nitrogen gas from a vertical nozzle and this temperature was maintained throughout the data collection. The infrared spectra of the $\alpha$ - and the $\gamma$ forms were recorded with a Brüker IFS $66 \mathrm{v} / \mathrm{S}$ infrared spectrometer.

Unit cell parameters and orientation matrix of the crystal were initially determined using $\sim 60$ reflections from 25 frames collected over a small $\omega$ scan of $7 \cdot 5^{\circ}$ sliced at $0 \cdot 3^{\circ}$ interval. A hemisphere of reciprocal space was then collected in two shells using the SMART software ${ }^{8}$ with $2 \theta$ settings of the detector at $28^{\circ}$ and 
$70^{\circ}$. Data reduction was performed using the SAINT program ${ }^{8}$ and the orientation matrix along with the detector and the cell parameters were refined for every 40 frames on all the measured reflections. The various experimental details are listed in table 1 . The crystal structure was first determined with the low-resolution data up to $\sin \theta / \lambda=0.56 \AA^{-1}$. The phase problem was solved by direct methods and the nonhydrogen atoms were refined anisotropically, by means of the full matrix least squares procedures using SHELXTL ${ }^{9}$. The $\mathrm{H}$ atom positions were found using the difference Fourier method and were adjusted to average neutron values ${ }^{10}\left(\mathrm{C}_{s p^{3}}-\mathrm{H}\right.$,

Table 1. Crystal data and experimental details.

\begin{tabular}{|c|c|c|c|}
\hline Crystal & $\alpha$ & $\gamma$ & $\alpha$-dimer \\
\hline Chemical formula & $\mathrm{C}_{11} \mathrm{H}_{12} \mathrm{O}_{3}$ & $\mathrm{C}_{11} \mathrm{H}_{12} \mathrm{O}_{3}$ & $\mathrm{C}_{22} \mathrm{H}_{24} \mathrm{O}_{6}$ \\
\hline Formula weight (g) & $192 \cdot 21$ & $192 \cdot 21$ & $384 \cdot 41$ \\
\hline Cell system & Triclinic & Monoclinic & Monoclinic \\
\hline Space group & $P-1$ & $C 2 / c$ & $P 2{ }_{1} / c$ \\
\hline$a(\AA)$ & $6 \cdot 69530(10)$ & $16 \cdot 9695(2)$ & $8 \cdot 333(4)$ \\
\hline$b(\AA)$ & $8 \cdot 67300(10)$ & $5 \cdot 46140(10)$ & $8 \cdot 444(2)$ \\
\hline$c(\AA)$ & $9 \cdot 98270(10)$ & $23 \cdot 0688(3)$ & $13.975(4)$ \\
\hline$\alpha\left(^{\circ}\right)$ & $72 \cdot 0270(10)$ & 90 & 90 \\
\hline$\beta\left(^{\circ}\right)$ & $71 \cdot 1900(10)$ & $110 \cdot 8560(10)$ & $106 \cdot 64(3)$ \\
\hline$\gamma\left({ }^{\circ}\right)$ & $67 \cdot 7830(10)$ & 90 & 90 \\
\hline$V\left(\mathrm{~cm}^{3}\right)$ & $496 \cdot 326(11)$ & $1997 \cdot 87(5)$ & $942 \cdot 0(6)$ \\
\hline$Z$ & 2 & 8 & 2 \\
\hline$F_{000}$ & 204 & 816 & 408 \\
\hline$\rho\left(\mathrm{Mg} \mathrm{m}^{-3}\right)$ & $1 \cdot 286$ & $1 \cdot 278$ & $1 \cdot 355$ \\
\hline Radiation type & Mo K $\alpha$ & & \\
\hline Wave length $(\AA)$ & 0.71073 & & \\
\hline $\begin{array}{l}\text { No. of reflections for cell } \\
\text { parameters }\end{array}$ & 60 & 60 & 60 \\
\hline$\mu\left(\mathrm{mm}^{-1}\right)$ & $0 \cdot 093$ & $0 \cdot 093$ & $0 \cdot 10$ \\
\hline Crystal form & Cuboidal & Needle & Cuboidal \\
\hline Crystal size (mm) & $0.3 \times 0.2 \times 0.2$ & $0.3 \times 0.15 \times 0.15$ & $0 \cdot 15 \times 0.1 \times 0 \cdot 1$ \\
\hline Crystal color & Colourless & Colourless & Colourless \\
\hline Data collection temperature & $130(2) \mathrm{K}$ & $130(2) \mathrm{K}$ & $130(2) \mathrm{K}$ \\
\hline Diffractometer & Siemens CCD & & \\
\hline Crystal-detector distance $(\mathrm{cm})$ & $5 \cdot 0$ & & \\
\hline No. of measured reflections & 7405 & 14190 & 9163 \\
\hline No. of independent reflections & 6365 & 8371 & 4928 \\
\hline No. of observed reflections & 4120 & 5079 & 3711 \\
\hline$R_{\text {int }}$ & $0 \cdot 0205$ & 0.0299 & $0 \cdot 0535$ \\
\hline$\theta_{\min }\left({ }^{\circ}\right)$ & $2 \cdot 21$ & $1 \cdot 89$ & $2 \cdot 55$ \\
\hline$\theta_{\max }\left({ }^{\circ}\right)$ & $49 \cdot 48$ & $49 \cdot 60$ & $49 \cdot 49$ \\
\hline \multirow[t]{3}{*}{ Range of $h, k, l$} & $-11 \leq h \leq 13$ & $-36 \leq h \leq 36$ & $-16 \leq h \leq 17$ \\
\hline & $-18 \leq k \leq 18$ & $-10 \leq k \leq 10$ & $-17 \leq k \leq 18$ \\
\hline & $-16 \leq l \leq 21$ & $-49 \leq l \leq 27$ & $-25 \leq l \leq 28$ \\
\hline \multicolumn{4}{|l|}{ After multipole refinement } \\
\hline Weighting scheme & $0 \cdot 07160,0 \cdot 1721$ & $0.0737,0.4$ & $0.0731,2 \cdot 7123$ \\
\hline$R 1$ & $0 \cdot 0426$ & $0 \cdot 0557$ & $0 \cdot 0417$ \\
\hline$w R 2$ & $0 \cdot 0467$ & 0.0654 & 0.0677 \\
\hline $\mathrm{S}$ & 0.9808 & 0.9622 & 0.9388 \\
\hline No. of variables & 278 & 278 & 278 \\
\hline$N_{\text {ref }} / N_{\mathrm{v}}$ & $14 \cdot 3$ & $18 \cdot 3$ & $13 \cdot 3$ \\
\hline
\end{tabular}


$1.06 \AA$; $\mathrm{C}_{s p^{2}}-\mathrm{H}, 1.075 \AA$; O-H, $0.96 \AA$ ) except in the case of the hydroxyl hydrogen of the $\gamma$-form, which was held at the position obtained from the structure determination (for details, see $\S 3$ ). Rigid bond tests of the various bonds were also carried out using TLS routine of the THMA14c program ${ }^{11}$. In all the structures studied, the bonds closely satisfied the Hirshfeld criterion ${ }^{12}$. The largest librational components obtained from the TLS analysis were 4.02, 4.03 and 5.6 degree ${ }^{2}$ for the $\alpha-, \gamma$ - and the dimer structures respectively.

Charge density analysis was carried out based on multipole expansion of the electron density centred at the nucleus of the atom ${ }^{13}$. Accordingly, the aspherical atomic density can be described in terms of spherical harmonics,

$$
\rho_{\text {atom }}(r)=\rho_{\text {core }}(r)+\rho_{\text {valence }}(r)+\rho_{\text {def }}(r) .
$$

Thus for each atom,

$$
\begin{aligned}
\rho_{\text {atom }}(r)= & \rho_{\text {core }}(r)+P_{v} \kappa^{3} \rho_{\text {valence }}(\kappa r) \\
& +\sum_{1=0} \kappa^{\prime 3} R_{1}\left(\kappa^{\prime} \zeta r\right) \sum_{m=0} \sum_{p= \pm 1} P_{\mathrm{lmp}} Y_{\mathrm{lmp}}(\theta, \varphi),
\end{aligned}
$$

with the origin at the atomic nucleus. The population coefficients, $P_{\operatorname{lmp}}$ are to be refined along with the $\kappa$ and $\kappa^{\prime}$ parameters. The kappa parameters control the radial dependence of the spherical and deformation valence densities. The analysis was carried out in several steps.

High-order refinement of the data was first performed using reflections with $\sin \theta / \lambda \geq 0.6 \AA^{-1}$ and $F_{0} \geq 4 \sigma$. All the hydrogens were held constant throughout the refinement along with their isotropic temperature factors. Multipolar refinement for the charge density analysis was carried out using the XDLSM routine of the XD package $^{14}$ and the details are given in table 1 . The atomic coordinates and the thermal parameters obtained from the high-order refinement were used as input to $\mathrm{XD}$ refinement. Oxygen and carbon atoms were refined up to octapole moments while hydrogens were restricted to dipole. Charge neutrality constraint was applied to the molecule during the refinement. The multipolar refinement strategy was the following: (a) Scale factor; (b) $P_{v}$; (c) $P_{\operatorname{lm}}$ (steps b and c until convergence); (d) $\mathrm{\kappa}$; (e) steps $b$ and $\mathrm{c}$ till convergence; (f) $\kappa^{\prime}$; (g) steps $\mathrm{b}$ and $\mathrm{c}$ till convergence; (h) positional and thermal parameters of all non-hydrogen atoms, and finally (i) $P_{v}$ and $P_{\mathrm{Im}}$ together. Static deformation density was obtained as a difference between the total density and the spherical density without the thermal smearing. Deformation density maps were plotted using the XDGRAPH routine. Residual maps obtained as the difference between the calculated and experimental densities were featureless, the magnitude of the random peaks being less than $0 \cdot 12 e \AA^{-3}$. The XDPROP routine was used to calculate the total electron density, $\rho(r)$, the Laplacian, $\nabla^{2} \rho$, and the ellipticity, $\varepsilon$, at the bond critical points (CPs). The value of $\rho_{\mathrm{CP}}$ is a measure of bond strength for a given pair of covalently bonded atoms ${ }^{15}$ while the Laplacian signifies the extent of depletion or concentration of bonding density. Ellipticity measures the extent of conjugation. Other bond properties such as the polarization $(\Delta \%)$ of the $\mathrm{CP}$ from the midpoint of the internuclear vector and its vertical displacement, $d$, denoting the polarity and the bent nature of a bond respectively, were also calculated. All the intramolecular CPs were of $(3,-1)$ type ${ }^{16}$ in $\rho(r)$ with negative Laplacians, characteristic of covalently bonded molecular systems ${ }^{17}$. Intermolecular 
hydrogen contacts as determined by the PARST program ${ }^{18}$ were of $(3,-1)$ type with positive Laplacians, characteristic of closed shell interactions.

\section{Results and discussion}

We shall first discuss the molecular structures in the $\alpha$ - and the $\gamma$-forms of $o$-ethoxy cinnamic acid. The $\alpha$-polymorph exists in a centrosymmetric triclinic system $\left(a=6.69530(10) \AA, \quad b=8.67300(10) \AA, \quad c=9.98270(10) \AA, \quad \alpha=72.0270(10)^{\circ}\right.$, $\left.\beta=71 \cdot 1900(10)^{\circ}, \gamma=67.7830(10)^{\circ}\right)$. The $\gamma$-form crystallizes in a monoclinic cell $\left(C 2 / c, a=16 \cdot 9695(2) \AA, b=5 \cdot 46140(10) \AA, c=23 \cdot 0688(3) \AA, \beta=110 \cdot 8560(10)^{\circ}\right)$.
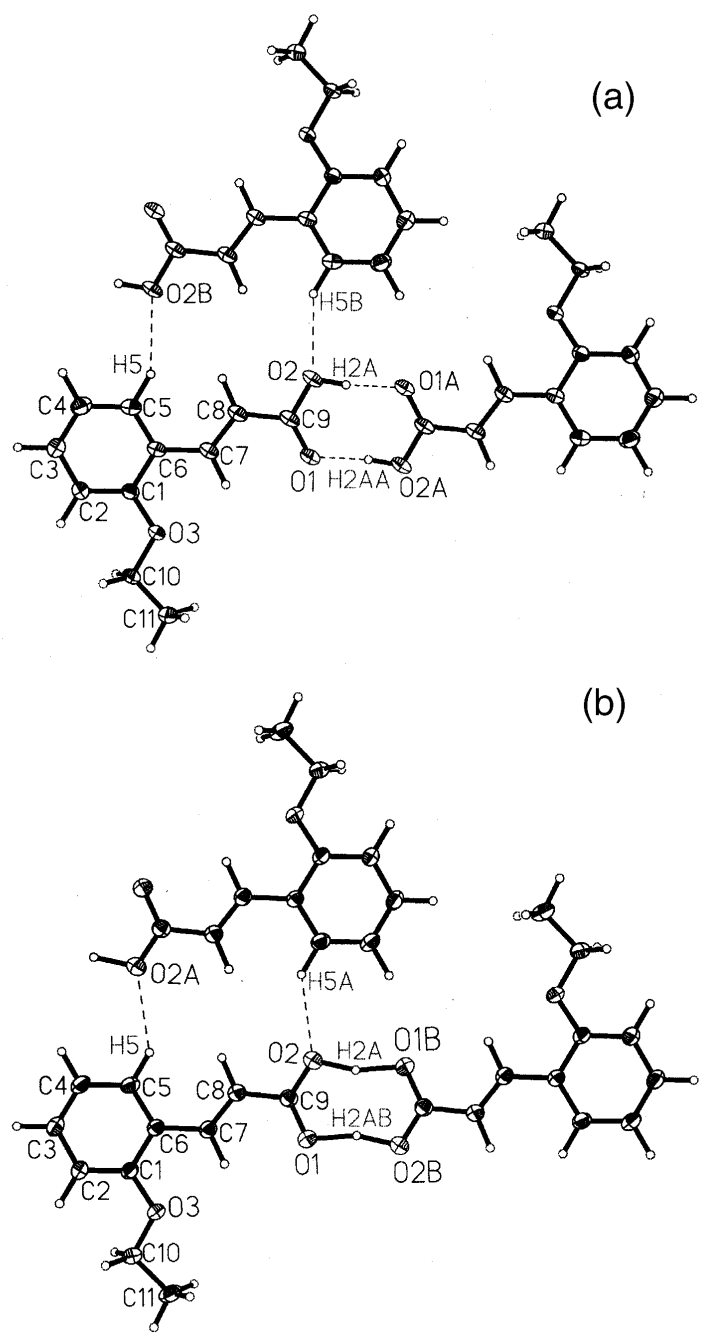

Figure 1. Packing diagrams of $o$-ethoxy cinnamic acid molecules in the (a) $\alpha$ and (b) $\gamma$-forms. Intermolecular contacts are also shown. All non-hydrogen atoms are shown at $50 \%$ probability ellipsoids. 
Table 2. Important differences in the molecular structure in the $\alpha$ - and $\gamma$-forms and the $\alpha$-dimer.

\begin{tabular}{|c|c|c|c|}
\hline & $\alpha$ & $\gamma$ & $\alpha$-dimer \\
\hline \multicolumn{4}{|l|}{ (a) Bond lengths $(\AA)$} \\
\hline$C(6)-C(7)$ & $1 \cdot 461(2)$ & $1 \cdot 462(2)$ & $1 \cdot 509(4)$ \\
\hline$C(7)-C(8)$ & $1 \cdot 345(2)$ & $1 \cdot 335(2)$ & $1 \cdot 549(4)$ \\
\hline$C(7)-C(8 A)^{a}$ & & & $1 \cdot 580(4)$ \\
\hline $\mathrm{C}(8)-\mathrm{C}(9)$ & $1 \cdot 468(2)$ & $1 \cdot 468(2)$ & $1.497(4)$ \\
\hline $\mathrm{O}(1)-\mathrm{C}(9)$ & $1 \cdot 240(2)$ & $1 \cdot 2710(14)$ & $1 \cdot 239(4)$ \\
\hline $\mathrm{O}(2)-\mathrm{C}(9)$ & 1·3161(14) & $1 \cdot 278(2)$ & $1 \cdot 307(4)$ \\
\hline $\mathrm{O}(2)-\mathrm{H}(2 \mathrm{~A})$ & 0.96 & $1 \cdot 25$ & 0.96 \\
\hline $\mathrm{C}(1)-\mathrm{O}(3)$ & $1 \cdot 3648(14)$ & $1 \cdot 3675(13)$ & $1 \cdot 373(4)$ \\
\hline $\mathrm{O}(3)-\mathrm{C}(10)$ & 1.4371(13) & $1 \cdot 431(2)$ & $1 \cdot 436(4)$ \\
\hline $\mathrm{C}(10)-\mathrm{C}(11)$ & $1 \cdot 506(2)$ & $1 \cdot 514(2)$ & $1 \cdot 507(6)$ \\
\hline \multicolumn{4}{|l|}{ (b) Bond angles $\left({ }^{\circ}\right)$} \\
\hline$C(5)-C(6)-C(7)$ & $122 \cdot 20(10)$ & $122 \cdot 74(10)$ & $119 \cdot 7(2)$ \\
\hline$C(6)-C(7)-C(8)$ & $125 \cdot 43(12)$ & $125 \cdot 78(10)$ & $118 \cdot 9(2)$ \\
\hline $\mathrm{C}(7)-\mathrm{C}(8)-\mathrm{C}(9)$ & $121 \cdot 06(12)$ & $121 \cdot 87(10)$ & $115 \cdot 1(2)$ \\
\hline$C(1)-C(6)-C(7)$ & $119 \cdot 57(10)$ & $119 \cdot 18(9)$ & $122 \cdot 4(2)$ \\
\hline $\mathrm{O}(2)-\mathrm{C}(9)-\mathrm{C}(8)$ & $113 \cdot 61(11)$ & $116 \cdot 56(10)$ & $114 \cdot 7(2)$ \\
\hline $\mathrm{O}(1)-\mathrm{C}(9)-\mathrm{C}(8)$ & $123 \cdot 5(2)$ & $120 \cdot 49(10)$ & $121 \cdot 9(3)$ \\
\hline $\mathrm{O}(3)-\mathrm{C}(1)-\mathrm{C}(6)$ & $116 \cdot 23(10)$ & $115 \cdot 88(9)$ & $114 \cdot 3(3)$ \\
\hline $\mathrm{C}(1)-\mathrm{O}(3)-\mathrm{C}(10)$ & $117 \cdot 79(9)$ & $118 \cdot 03(9)$ & $118 \cdot 3(2)$ \\
\hline $\mathrm{O}(3)-\mathrm{C}(10)-\mathrm{C}(11)$ & $107 \cdot 35(10)$ & $106 \cdot 97(11)$ & $107 \cdot 0(3)$ \\
\hline \multicolumn{4}{|l|}{ (c) Torsion angles $\left({ }^{\circ}\right)$} \\
\hline $\mathrm{C}(5)-\mathrm{C}(6)-\mathrm{C}(7)-\mathrm{C}(8)$ & $1 \cdot 6(2)$ & $5 \cdot 05(18)$ & $-125 \cdot 8(3)$ \\
\hline $\mathrm{C}(2)-\mathrm{C}(1)-\mathrm{C}(6)-\mathrm{C}(7)$ & $-178 \cdot 68(12)$ & $-179 \cdot 28(10)$ & $176 \cdot 5(3)$ \\
\hline $\mathrm{C}(1)-\mathrm{C}(6)-\mathrm{C}(7)-\mathrm{C}(8)$ & $-179 \cdot 56(12)$ & $-175 \cdot 68(11)$ & $54 \cdot 4(4)$ \\
\hline $\mathrm{C}(6)-\mathrm{C}(7)-\mathrm{C}(8)-\mathrm{C}(9)$ & $-178 \cdot 34(12)$ & $177 \cdot 94(10)$ & $109 \cdot 9(3)$ \\
\hline $\mathrm{C}(7)-\mathrm{C}(8)-\mathrm{C}(9)-\mathrm{O}(2)$ & $-177 \cdot 01(12)$ & $175 \cdot 33(11)$ & $160 \cdot 4(2)$ \\
\hline $\mathrm{C}(7)-\mathrm{C}(8)-\mathrm{C}(9)-\mathrm{O}(1)$ & $3 \cdot 7(2)$ & $-5 \cdot 60(18)$ & $-22 \cdot 6(4)$ \\
\hline $\mathrm{C}(1)-\mathrm{O}(3)-\mathrm{C}(10)-\mathrm{C}(11)$ & $-178 \cdot 87(11)$ & $174 \cdot 06(11)$ & $-174 \cdot 7(3)$ \\
\hline $\mathrm{C}(10)-\mathrm{O}(3)-\mathrm{C}(1)-\mathrm{C}(6)$ & $-177 \cdot 98(11)$ & $-173 \cdot 18(11)$ & $-179 \cdot 0(3)$ \\
\hline $\mathrm{C}(10)-\mathrm{O}(3)-\mathrm{C}(1)-\mathrm{C}(2)$ & $1 \cdot 67(18)$ & $7 \cdot 07(17)$ & $2 \cdot 7(5)$ \\
\hline
\end{tabular}

${ }^{\mathrm{a}}$ The distances between the shortest double bond contact in $\alpha$ - and $\gamma$-form are 4.514 and $5 \cdot 253 \AA$ respectively

In both these polymorphs, the asymmetric unit comprises a full molecule. We show the molecular packing diagrams of the $\alpha$ - and $\gamma$-forms in figure 1 . The structural parameters of the two forms are listed in table 2 along with those of the photodimer, to highlight the differences. We notice that the bond distances and angles in the phenyl ring as well as the double bond regions are similar, while the ethoxy groups of the two forms exhibit small differences. The torsion angles of the ethoxy and the double bond group regions are, however, noticeably different in the two forms. The molecule is non-planar in the $\gamma$-form, the groups being twisted away from the plane of the benzene ring by as much as $9^{\circ}$. In the $\alpha$-form, the heavy atom framework of the molecule is essentially planar, the side groups being out of plane of the benzene ring by $\sim 3^{\circ}$. 
In table 3, we list favourable hydrogen contacts in the $\alpha$ - and $\gamma$-structures. There are intermolecular $\mathrm{O}-\mathrm{H} \cdots \mathrm{O}$ contacts between the carboxyl groups in both the forms, but the nature of these contacts is entirely different. Thus, $\mathrm{C}(9)-\mathrm{O}$ bond lengths in the $\alpha$-form are 1.240(2) and 1.3161(14) $\AA$ respectively, while these distances are nearly equal $(\sim 1.275 \AA)$ in the $\gamma$-form. The intermolecular $\mathrm{O} \cdots \mathrm{O}$ distance in the $\alpha$ form is slightly longer than in the $\gamma$-form $(\alpha, 2 \cdot 633(1) ; \gamma, 2 \cdot 617(2) \AA)$. C (8)-C(9)$\mathrm{O}(1)$ and $\mathrm{C}(8)-\mathrm{C}(9)-\mathrm{O}(2)$ bond angles show the some differences as well. The angles are $123.5(2)^{\circ}$ and $113.61(11)^{\circ}$ respectively in the $\alpha$-form and are closer in the $\gamma$-form, $120 \cdot 49(10)^{\circ}$ and $116 \cdot 56(10)^{\circ}$ respectively. These structural features suggest the presence of a near-symmetric hydrogen bond in the carboxylic dimer in the $\gamma$-form and normal dimer hydrogen bond in the $\alpha$-form. The two carboxylic bond angles approaching a common value and the bonds becoming nearly equal is in accordance with the VSEPR model. In order to explore how common such a feature is, a search was carried out using the Cambridge Structural Database (version 5.7) for carboxylic acids having the two $\mathrm{C}-\mathrm{O}$ bonds differing within $0.01 \AA$. Of the total of 3334 acid groups found, only $3 \%$ could satisfy this criterion. Among half of these, HFIX had been applied for positioning hydroxyl hydrogen. Where hydrogen has been located, the $\mathrm{O}-\mathrm{H}$ bond length ranges between 1.0 and $1.31 \AA$. Accordingly, the carboxylic hydrogen, $\mathrm{H}(2 \mathrm{~A})$ in the $\gamma$-form was located midway in the intermolecular region with $\mathrm{O}-\mathrm{H}$ and $\mathrm{H} \cdots \mathrm{O}$ distances being 1.25 and $1.40 \AA$ respectively. This hydrogen was held at this position in the subsequent refinements. The corresponding distances in the $\alpha$-form are 0.96 and $1.68 \AA$ respectively (see tables 2 and 3 ).

Table 3. Intra- and intermolecular hydrogen bond contacts.

\begin{tabular}{|c|c|c|c|c|c|}
\hline Polymorph & D-H...A & Bond type & H...A & $\mathrm{D} \cdots \mathrm{A}$ & $\angle \mathrm{D}-\mathrm{H} \ldots \mathrm{A}$ \\
\hline \multirow[t]{6}{*}{$\alpha$-form } & $\mathrm{O}(2)-\mathrm{H}(2 \mathrm{~A}) \cdots \mathrm{O}(1)^{\mathrm{a}}$ & Acid dimer & $1 \cdot 68(2)$ & $2 \cdot 633(1)$ & $172 \cdot 1(6)$ \\
\hline & $\mathrm{C}(5)-\mathrm{H}(5) \cdots \mathrm{O}(2)^{\mathrm{b}}$ & Intralayer & $2 \cdot 437(1)$ & $3 \cdot 404(2)$ & $148 \cdot 9(1)$ \\
\hline & $\mathrm{C}(4)-\mathrm{H}(4) \cdots \mathrm{O}(1)^{\mathrm{c}}$ & Interlayer & $2 \cdot 637(1)$ & $3 \cdot 634(2)$ & $153 \cdot 9(1)$ \\
\hline & $\mathrm{C}(10)-\mathrm{H}(10 \mathrm{~A}) \cdots \mathrm{O}(3)^{\mathrm{d}}$ & Interlayer & $2 \cdot 930(2)$ & $3 \cdot 616(2)$ & $122 \cdot 9(1)$ \\
\hline & $\mathrm{C}(10)-\mathrm{H}(10 \mathrm{~B}) \cdots \mathrm{O}(1)^{\mathrm{e}}$ & Interlayer & $2 \cdot 600(1)$ & $3 \cdot 315(1)$ & $124 \cdot 3(1)$ \\
\hline & $\mathrm{C}(11)-\mathrm{H}(11 \mathrm{C}) \cdots \mathrm{O}(2)^{\mathrm{f}}$ & Interlayer & $2 \cdot 675(2)$ & $3 \cdot 648(2)$ & $152 \cdot 4(1)$ \\
\hline \multirow[t]{5}{*}{$\gamma$-form } & $\mathrm{O}(2)-\mathrm{H}(2 \mathrm{~A}) \cdots \mathrm{O}(1)^{\mathrm{g}}$ & Acid dimer & $1 \cdot 40(1)$ & $2 \cdot 617(2)$ & $162 \cdot 4(8)$ \\
\hline & $\mathrm{C}(5)-\mathrm{H}(5) \cdots \mathrm{O}(2)^{\mathrm{f}}$ & Intralayer & $2 \cdot 481(1)$ & $3 \cdot 386(1)$ & $141 \cdot 2(1)$ \\
\hline & $\mathrm{C}(4)-\mathrm{H}(4) \cdots \mathrm{O}(1)^{\mathrm{i}}$ & Interlayer & $2 \cdot 615(1)$ & $3 \cdot 641(1)$ & $159 \cdot 4(1)$ \\
\hline & $\mathrm{C}(10)-\mathrm{H}(10 \mathrm{~B}) \cdots \mathrm{O}(3)^{\mathrm{j}}$ & Interlayer & $2 \cdot 818(1)$ & $3 \cdot 690(1)$ & $139 \cdot 6(1)$ \\
\hline & $\mathrm{C}(11)-\mathrm{H}(11 \mathrm{~B}) \cdots \mathrm{O}(1)^{\mathrm{k}}$ & Interlayer & $2 \cdot 939(1)$ & $3 \cdot 714(1)$ & $130 \cdot 3(1)$ \\
\hline \multirow[t]{6}{*}{$\alpha$-dimer } & $\mathrm{O}(2)-\mathrm{H}(2 \mathrm{~A}) \cdots \mathrm{O}(1)^{1}$ & Acid dimer & $1 \cdot 67(2)$ & $2 \cdot 627(3)$ & $174(5)$ \\
\hline & $\mathrm{C}(7)-\mathrm{H}(7) \cdots \mathrm{O}(3)^{\mathrm{m}}$ & Intramolecular & $2 \cdot 42(4)$ & $2 \cdot 938(4)$ & $108(2)$ \\
\hline & $\mathrm{C}(8)-\mathrm{H}(8) \cdots \mathrm{O}(3)^{\mathrm{n}}$ & Intramolecular & $2 \cdot 75(4)$ & $3 \cdot 176(3)$ & $103(2)$ \\
\hline & $\mathrm{C}(11)-\mathrm{H}(11 \mathrm{~B}) \cdots \mathrm{O}(1)^{\mathrm{m}}$ & Intramolecular & $2 \cdot 67(5)$ & $3 \cdot 525(5)$ & $137(4)$ \\
\hline & $\mathrm{C}(4)-\mathrm{H}(4) \cdots \mathrm{O}(2)^{\mathrm{p}}$ & Intermolecular & $2 \cdot 60(3)$ & $3 \cdot 493(4)$ & $140(3)$ \\
\hline & $\mathrm{C}(11)-\mathrm{H}(11 \mathrm{~A}) \cdots \mathrm{O}(1)^{\mathrm{q}}$ & Intermolecular & $2 \cdot 55(5)$ & $3 \cdot 490(4)$ & $148(3)$ \\
\hline
\end{tabular}

Symmetry: (a) $-1-x, 2-y,-z$; (b) $-1-x, 3-y,-z$; (c) $x, 1+y, z$; (d) $-x, 2-y, 1-z$; (e) $1+x, y, z$; (f) $-x, 2-y,-z$; (g) $\frac{1}{2}-x, 5 / 2+y, \frac{1}{2}-z$; (i) $-\frac{1}{2}-x,-\frac{1}{2}+y, z$; (j) $\frac{1}{2}-x,-\frac{1}{2}+y, \frac{1}{2}-y$; (k) $x, y-1, z$; (1) $-1-x,-y, z ;(\mathrm{m})-x,-y,-z ;$ (n) $x, y, z ;$ (p) $x, \frac{1}{2}-y,-\frac{1}{2}+z$; (q) $x, \frac{1}{2}-y, \frac{1}{2}-z$ 
As shown in figure 1 , each molecule is held by two $\mathrm{C}-\mathrm{H} \cdots \mathrm{O}$ contacts from an adjacent molecule related by inversion. In the $\alpha$-form, this contact is at 2.437(1) $\AA$, almost perpendicular to the $\mathrm{O}-\mathrm{H} \cdots \mathrm{O}$ contacts. The contact in the $\gamma$-form is longer by $\sim 0.05 \AA$ and is slightly tilted following reorientation of the carboxylic group. The molecules pack in layers in both the forms, the spacing between the layers being $\sim 3.45$ and $3.39 \AA$ respectively in the $\alpha$ - and the $\gamma$-forms. The relative positions of the benzene rings in a layer do not differ appreciably in the two polymorphs and the crystal densities are also comparable (see table 1). The layers are held by $\mathrm{C}-\mathrm{H} \cdots \mathrm{O}$ contacts, four in the $\alpha$-form and three in $\gamma$-form, the distances ranging between 2.60 and $2.94 \AA$ (see table 3 ). The adjacent layers are less displaced with respect to one another in the $\alpha$-form, with more favourable contacts in terms of the distance and the angle. The differences in the structural features of the $\alpha$ - and the $\gamma$-forms discussed hitherto play an important role in determining the photoreactivity. We shall discuss this aspect along with the charge density, later in the paper.

We felt that the difference between the $\alpha$ - and the $\gamma$-forms with respect to the nature of hydrogen bonding in the carboxylic acid dimer needs further proof by an independent method. Since infrared (IR) spectroscopy is ideally suited to distinguish symmetric and asymmetric hydrogen bonds ${ }^{19,20}$, we carried out a comparative study of the IR spectra of the $\alpha$ - and the $\gamma$-forms in the $4000-400 \mathrm{~cm}^{-1}$ region. The spectra were recorded in the form of $\mathrm{KBr}$ pellets as well as nujol mulls. The nujol mull spectra were considered essential in order to avoid spurious bands due to any moisture in $\mathrm{KBr}$. In figure 2, we show the IR spectra of the two forms in the 33002200 and $1900-1500 \mathrm{~cm}^{-1}$ regions. While the spectrum of the $\gamma$-form shows a larger number of features due to the lower symmetry as expected, the most prominent difference in the spectra of the two forms is seen in the $3300-2200 \mathrm{~cm}^{-1}$ region. The $\alpha$-form shows a broad intense band centred around $3000 \mathrm{~cm}^{-1}$, in addition to weak features between 2800 and $2500 \mathrm{~cm}^{-1}$. Such features are characteristic of carboxylic acid dimmers ${ }^{19,21}$. The intense band centred around $3000 \mathrm{~cm}^{-1}$ is completely absent in the spectrum of the $\gamma$-form. One of the characteristic features of symmetric hydrogen bonds is the absence of $3000 \mathrm{~cm}^{-1}$ band in the hydrogen bond region ${ }^{20,22}$. The $\alpha$-form shows bands at $\sim 1730$ and $1694 \mathrm{~cm}^{-1}$ due to the $\mathrm{OH}$ bending and the $\mathrm{C}=\mathrm{O}$ stretching modes respectively. We observe the $\mathrm{C}=\mathrm{O}$ stretching mode at $\sim 1688 \mathrm{~cm}^{-1}$ in the spectrum of the $\gamma$-form, the lower $\mathrm{C}=\mathrm{O}$ frequency being consistent with the stronger hydrogen bonds present in the dimer. The absence of the $\mathrm{OH}$ bending frequency suggests that the hydrogen bond in the $\gamma$-form is different from that in the ordinary cyclic dimers. A symmetric H-bond does not exhibit such a bending vibration frequency. Furthermore, the appearance of additional bands at 1622 and $1598 \mathrm{~cm}^{-1}$ in the spectrum of the $\gamma$-form also supports this observation $^{20,22}$. The IR spectrum of maleate ion shows the $\mathrm{O}-\mathrm{H}$ stretching band below $1650 \mathrm{~cm}^{-1}$. Based on the IR studies, we can safely conclude that the $\gamma$-form has symmetric hydrogen bonds while the $\alpha$-form possesses the usual carboxylic acid dimers.

The photodimer of the $\alpha$-polymorph, 2,2'-diethoxy $\alpha$-truxillic acid, crystallizes in a centrosymmetric space group, $\quad P 2_{1} / c \quad(a=8.333(4) \AA, \quad b=8.444(2) \AA$, $\left.c=13.975(4) \AA, \beta=106 \cdot 64(3)^{\circ}\right)$ with two molecules per unit cell, the asymmetric unit being half the molecule. The $\mathrm{C}(7)-\mathrm{C}(8)$ distance in the cyclobutyl ring is $1 \cdot 549$ (4) $\AA$, about $0 \cdot 2 \AA$ longer compared to the pristine $\alpha$-form. The internal 


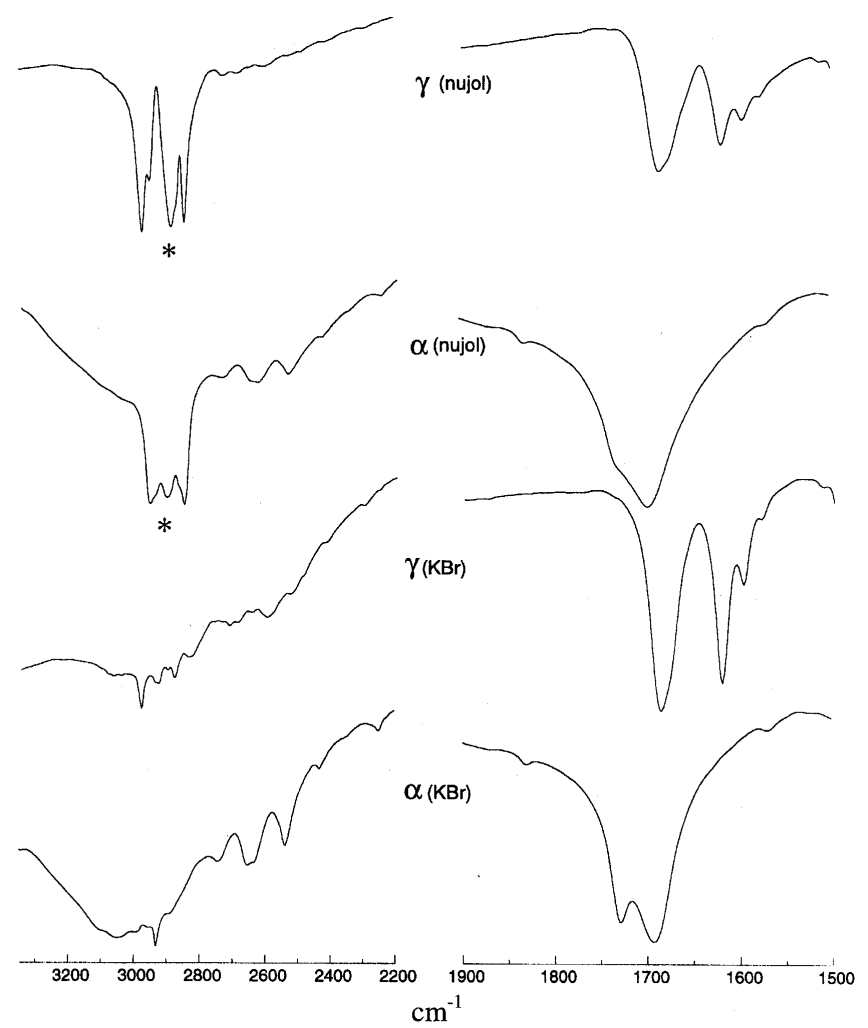

Figure 2. Infrared spectra of the $\alpha$ - and the $\gamma$-forms of $o$-ethoxy cinnamic acid in $\mathrm{KBr}$ pellet and nujol mull. Asterisks denote nujol bands.

geometry of this ring is quite comparable to that found in $\alpha$-truxilic acid ${ }^{2}$. The bond angles change dramatically, the angles around $\mathrm{C}(7)$ and $\mathrm{C}(8)$ become nearly tetrahedral on dimerization (see table 2). The $\mathrm{C}(6)-\mathrm{C}(7)$ and $\mathrm{C}(8)-\mathrm{C}(9)$ distances increase by $\sim 0.04 \AA$ and $0.03 \AA$ respectively. The bond distances increase by $\sim 0.01 \AA$ in the ethoxy groups. The regions of the benzene ring exhibit minor changes on dimerization, but the angular relations with the side groups undergo major changes. Thus, the cyclobutyl ring and the acid groups subtend angles of $\sim 89.4^{\circ}$ and $46.3^{\circ}$ respectively with the phenyl ring, while the ethoxy group makes an angle of $5.4^{\circ}$ with the phenyl ring (compared to $2.6^{\circ}$ in the $\alpha$-form). In figure 3 , we show the packing diagram of the photodimer viewed along the $b$-axis. The $\mathrm{O}-\mathrm{H} \cdots \mathrm{O}$ contacts of the acid dimeric units run parallel to the $a$-axis, providing enough scope for several $\mathrm{C}-\mathrm{H} \cdots \mathrm{O}$ side interactions (table 3 ). The methyl hydrogen, $\mathrm{H}(11 \mathrm{~A})$ establishes an intermolecular contact with a carbonyl oxygen while $\mathrm{H}(11 \mathrm{~B})$ forms an intramolecular contact with it. The phenyl hydrogen, $\mathrm{H}(4)$ enters into intermolecular contact with a neighbouring hydroxyl oxygen, $\mathrm{O}(2)$. Unlike the monomers, $\mathrm{H}(5)$ in the dimer is no longer in a position to form a $\mathrm{C}-\mathrm{H} \cdots \mathrm{O}$ contact. 


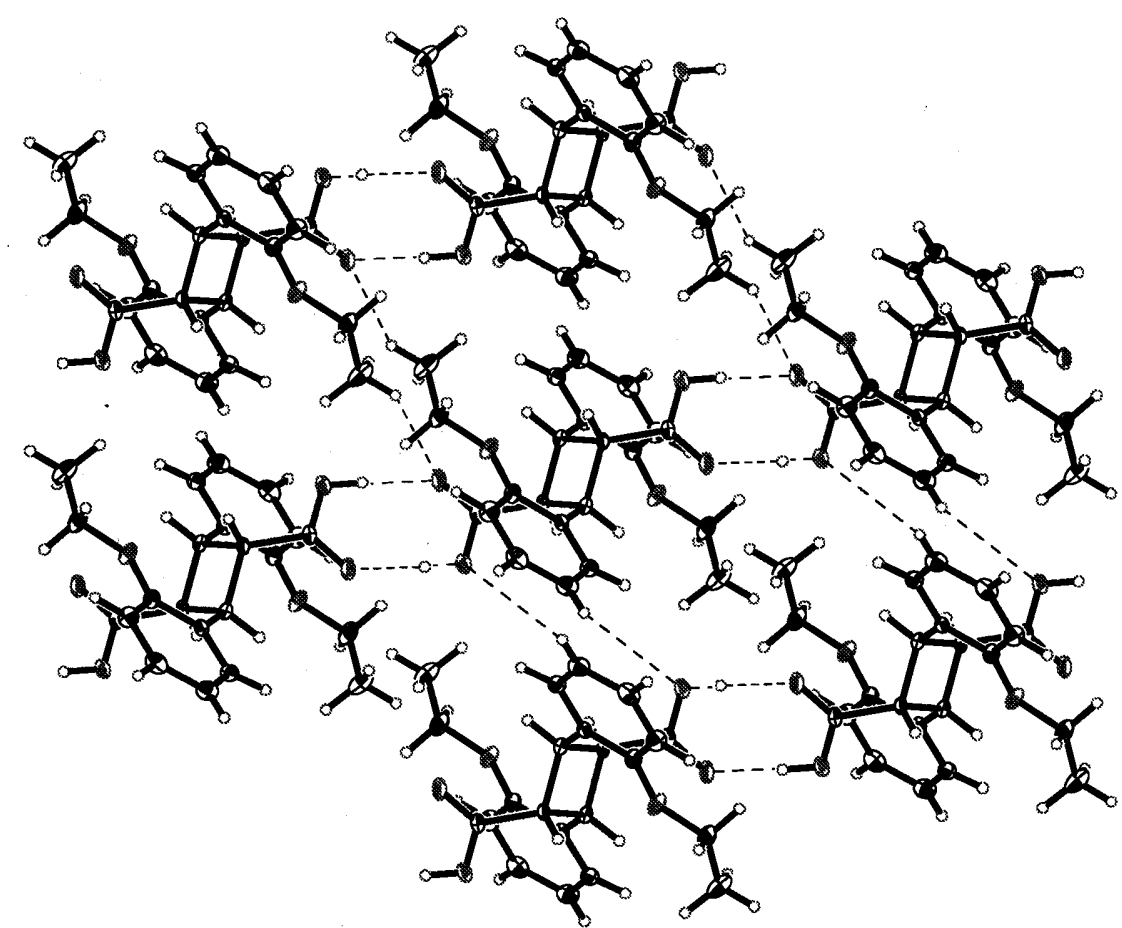

Figure 3. Packing diagram of the photodimer, 2,2'-diethoxy $\alpha$-truxillic acid. Intra- and intermolecular contacts are also shown. All non-hydrogen atoms are shown at $50 \%$ probability ellipsoids.

In figure 4 we show two centrosymmetric molecules in the $\alpha$-form undergoing photodimerization. The molecules belong to adjacent layers and are related by $(-x$, $2-y,-z)$. The double bonds $(1 \cdot 345(2) \AA)$ between $\mathrm{C}(7)$ and $\mathrm{C}(8)$ of the cinnamoyl groups may be considered the opposite sides of an imaginary rectangle distorted by $\sim 3.1^{\circ}$. Although the distance between the double bonds $(4.514 \AA)$ is somewhat larger than required by the Schmidt criterion ${ }^{1}$, the bonds are potentially reactive. In the photostable $\gamma$-form, however, the $\mathrm{C}(7)=\mathrm{C}(8)$ bond sticks out of the molecular plane $\left(\mathrm{C}(1)-\mathrm{C}(6)-\mathrm{C}(7)-\mathrm{C}(8),-175 \cdot 68(11)^{\circ}, \mathrm{C}(5)-\mathrm{C}(6)-\mathrm{C}(7)-\mathrm{C}(8), 5.05(18)^{\circ}\right.$ as compared to $-179.56(12)^{\circ}$ and $1.6(2)^{\circ}$ in the $\alpha$-form) and as a result its reactive partner $\left(\frac{1}{2}-x, \frac{3}{2}-y,-z\right)$ is placed farther apart $(\sim 5.251 \AA)$ in an oblique parallelogram (see inset of figure 4 ), the acute angle being $80 \cdot 7^{\circ}$. The cyclobutane ring formed by the dimerization of the $\alpha$-form is not an exact square $(1.549 \AA \times 1.580 \AA)$, the new $\mathrm{C}(7)-\mathrm{C}(8 \mathrm{~A})$ and $\mathrm{C}(8)-\mathrm{C}(7 \mathrm{~A})$ bonds are slightly longer than the $\mathrm{C}(7)-\mathrm{C}(8)$ bonds and the angular distortion is $1 \cdot 8^{\circ}$. Probably, the eclipsing interactions between $\mathrm{C}(6)$ of the phenyl ring and $\mathrm{C}(9 \mathrm{~A})$ of the carboxylic group bring about subtle differences in bond lengths between the two pairs. The two halves of the dimer are related by inversion as expected from the topochemistry of the dimerization.

We now turn to the charge density analysis of the cinnamic acid monomers in the $\alpha$ - and the $\gamma$-forms and of the photodimer. In figure 5, we show the deformation density in a plane containing $\mathrm{C}(4), \mathrm{C}(9)$ and $\mathrm{C}(11)$ atoms of the $\alpha$ - and $\gamma$ - 


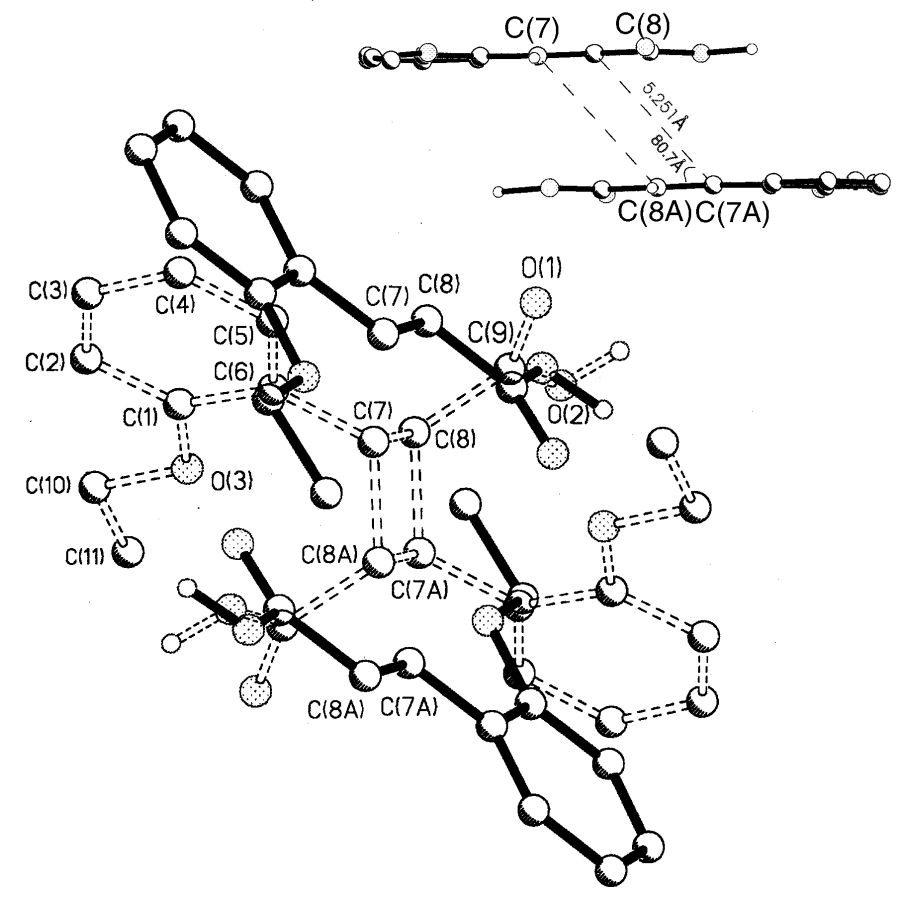

Figure 4. Photodimerization in $o$-ethoxy cinnamic acid. Two centrosymmetric molecules of the $\alpha$-form before (full lines) and after (dashed lines) the reaction. Hydrogen atoms other than the hydroxylic are omitted from the figure for the sake of clarity. The inset shows an equivalent region containing two centrosymmetric molecules of the $\gamma$-form.

polymorphs. Concentric contours typify the various bonding regions in the molecules between the atom-cores. The lone-pair electrons on the ethoxy and carboxylic oxygens are clearly seen as pairs of lobes. The total electron densities and the Laplacians at the critical points are listed for the various bonds in table 4 along with the polarization and ellipticity parameters. The average $\rho_{\mathrm{CP}}$ of the phenyl ring is $2.11 e \AA^{-3}$ in the $\alpha$-form as compared to $2.19 e \AA^{-3}$ in the $\gamma$-form. Similarly, the $\mathrm{C}(6)-\mathrm{C}(7)$ and $\mathrm{C}(8)-\mathrm{C}(9)$ single bond regions in the $\alpha$-form have densities of $1.78(4)$ and $1.82(5) e \AA^{-3}$ respectively while those in the $\gamma$-form exhibit somewhat higher values, 1.96(4) and 1.95(5)e $\AA^{-3}$ respectively. In the $\gamma$-form, the topography of the deformation density in the $\mathrm{C}(7)=\mathrm{C}(8)$ region is as expected of a carboncarbon double bond ${ }^{23}$. In the $\alpha$-form, on the other hand, the contours are less dense (see figure 5). This is reflected in the properties of the bond CPs. In the $\gamma$-form, the density between $\mathrm{C}(7)$ and $\mathrm{C}(8)$ is $2.55(5) e \AA^{-3}$, typical of an isolated double bond ${ }^{15}$ while in the $\alpha$-form, it is considerably lower $\left(2 \cdot 27(5) e \AA^{-3}\right)$ though the corresponding bond lengths hardly differ (table 2). The bond in the $\alpha$-form is associated with slightly higher ellipticity. The ethoxy groups in the $\alpha$ - and $\gamma$-forms also show differences in bond densities. The $\mathrm{C}(1)-\mathrm{O}(3)$ bond in the $\alpha$-form has much higher density $\left(2 \cdot 21(5) e \AA^{-3}\right)$ than the $\mathrm{O}(3)-\mathrm{C}(10)$ bond $\left(1 \cdot 80(5) e \AA^{-3}\right)$, 

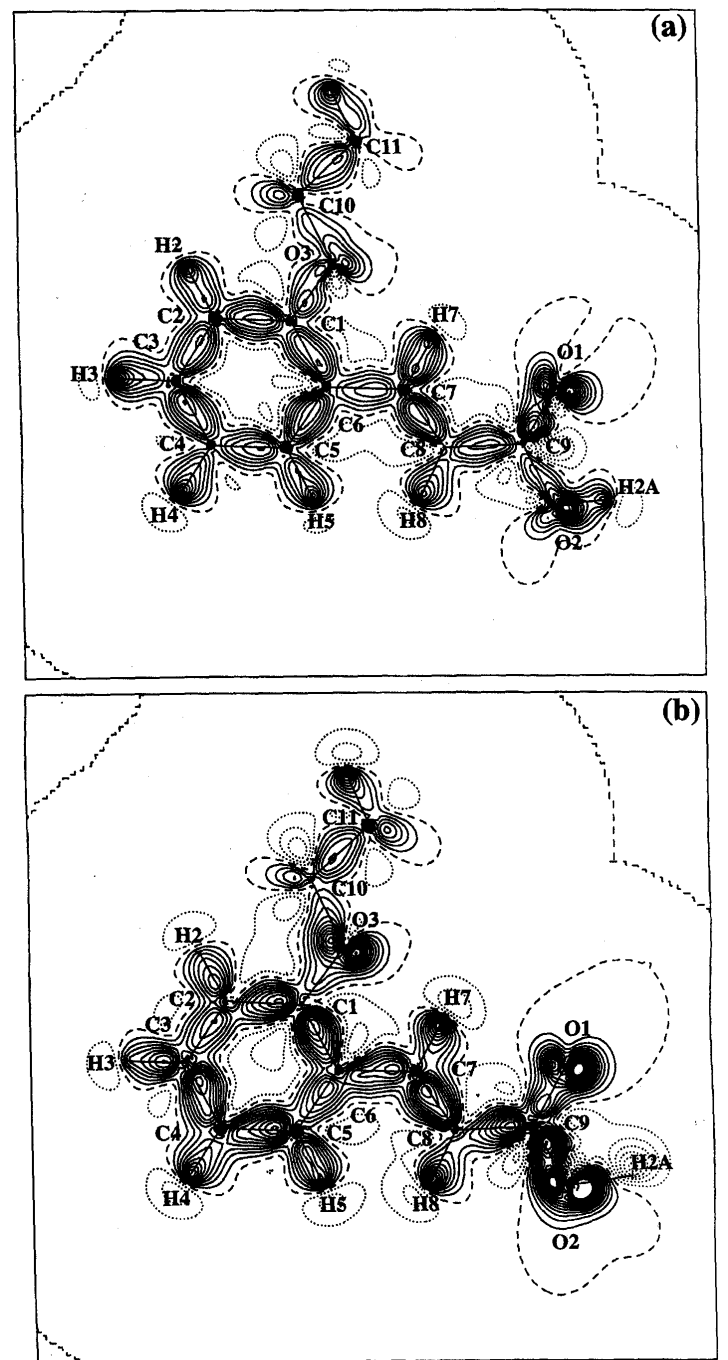

Figure 5. Deformation density maps in the mean plane of the molecule in the (a) $\alpha$ - and (b) $\gamma$-forms. Deformation density was obtained as the difference between the total density and the spherical density without thermal smearing. Contour interval $=0 \cdot 1 e \AA^{-3}$.

indicating that the density has migrated from one bond to the other. The difference is much smaller in the $\gamma$-form $\left(\sim 0 \cdot 2 e \AA^{-3}\right)$. Considering that the molecule is quite planar in the $\alpha$-form we would expect such differences due to conjugation ${ }^{24}$.

As regards the $\mathrm{C}-\mathrm{H} \cdots \mathrm{O}$ hydrogen contacts, all except $\mathrm{C}(10)-\mathrm{H}(10 \mathrm{~B}) \cdots \mathrm{O}(1)$ are associated with small densities and Laplacians in both the polymorphs. The $\mathrm{C}(10)-$ $\mathrm{H}(10 \mathrm{~B}) \cdots \mathrm{O}(1)$ contact exists only in the $\alpha$-form and carries a density of $0.052(7)$ $e \AA^{-3}$ and a positive Laplacian $\left(0 \cdot 759(4) e \AA^{-5}\right)$ as expected. Following Mallinson $e t$ 


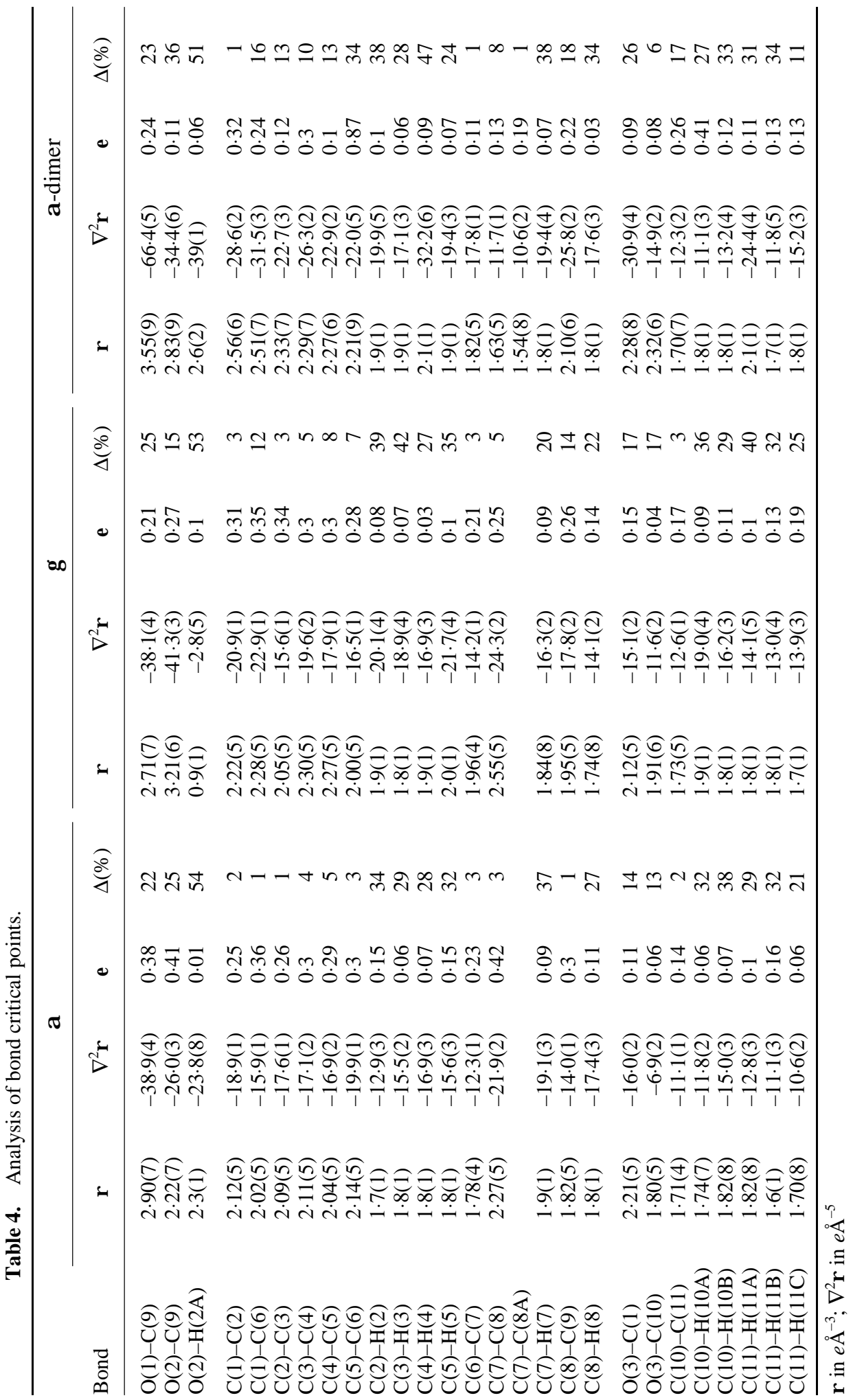


$a l^{25}$, it can be considered as a moderately strong $\mathrm{C}-\mathrm{H} \cdots \mathrm{O}$ interaction. However, the intermolecular $\mathrm{O}-\mathrm{H} \cdots \mathrm{O}$ contacts in the two forms exhibit major differences in charge density in parallel to the structural differences discussed earlier. In this context, the deformation density maps in the carboxylic dimer region are revealing. We see from figure 5 that there are considerable differences in the charge density in this region (see tables 4 and 5). Thus, the $\mathrm{C}(9)=\mathrm{O}(1), \mathrm{C}(9)-\mathrm{O}(2)$ and the $\mathrm{O}(2)-$ $\mathrm{H}(2 \mathrm{~A})$ regions in the $\alpha$-form have $\rho_{\mathrm{CP}}$ values of $2.90(7), 2 \cdot 22(7)$ and $2 \cdot 3(1) e \AA^{-3}$ respectively. The $\mathrm{O}(2)-\mathrm{H}(2 \mathrm{~A}) \cdots \mathrm{O}(1 \mathrm{~A})$ bond carries a small density of $0 \cdot 28(7) e \AA^{-3}$ and a positive Laplacian of 5.13(8)e $\AA^{-5}$, characteristic of closed-shell interaction in the intermolecular region. The near absence of distinction between the two $\mathrm{C}-\mathrm{O}$ bond lengths of the carboxyl group in the $\gamma$-form is reflected in the charge distribution. The densities associated with $\mathrm{C}(9)=\mathrm{O}(1)$ and $\mathrm{C}(9)-\mathrm{O}(2)$ bonds are unusually high, 2.71(7) and 3.21(6) $e \AA^{-3}$ respectively. Moreover, we find comparable densities in the $\mathrm{O}-\mathrm{H}$ and the $\mathrm{H} \cdots \mathrm{O}$ bonds $\left(0 \cdot 9(1)\right.$ and $0.6(1) e \AA^{-3}$ respectively), the associated Laplacians being $-2 \cdot 8(5)$ and 1.9(2) $e \AA^{-5}$ respectively. Contour maps of the Laplacian shown in figure 6 illustrate the ionic nature of the $\mathrm{O}-\mathrm{H}$ bond in the $\gamma$-form as compared to a shared interaction in the $\alpha$-form. This is one of the few instances where the charge density distribution of a near-symmetric intermolecular hydrogen bond has been studied. In maleates containing intramolecular symmetric hydrogen bonds $(\mathrm{O} \cdots \mathrm{H} \sim 1 \cdot 21 \AA)$, the values of $\rho_{\mathrm{CP}}$ and Laplacian are $\sim 1 \cdot 1 e \AA^{-3}$ and $-6 e \AA^{-5}$ respectively ${ }^{5}$.

Inspection of the pseudo-atomic charges reveals that there is interplay between the resonance and inductive effects in the molecule. The charge on $\mathrm{O}(1), \mathrm{O}(2)$ and $\mathrm{H}(2 \mathrm{~A})$ in the $\gamma$-form was found to be higher $(-0.47,-0.48$ and $0.63 e)$ than those in

Table 5. Hydrogen bond critical points.

\begin{tabular}{lllll}
\hline Polymorph & \multicolumn{1}{c}{$\mathrm{D}-\mathrm{H} \ldots \mathrm{A}$} & Bond type & $\rho\left(e \AA^{-3}\right)$ & $\nabla^{2} \rho\left(e \AA^{-5}\right)$ \\
\hline$\alpha$-form & $\mathrm{O}(2)-\mathrm{H}(2 \mathrm{~A}) \cdots \mathrm{O}(1)^{\mathrm{a}}$ & Acid dimer & $0 \cdot 28(7)$ & $5 \cdot 13(8)$ \\
& $\mathrm{C}(5)-\mathrm{H}(5) \cdots \mathrm{O}(2)^{\mathrm{b}}$ & Intralayer & $0 \cdot 04(2)$ & $0 \cdot 811(4)$ \\
& $\mathrm{C}(4)-\mathrm{H}(4) \cdots \mathrm{O}(1)^{\mathrm{c}}$ & Interlayer & $0 \cdot 02(1)$ & $0 \cdot 438(5)$ \\
& $\mathrm{C}(10)-\mathrm{H}(10 \mathrm{~A}) \cdots \mathrm{O}(3)^{\mathrm{d}}$ & Interlayer & $0 \cdot 023(3)$ & $0 \cdot 355(2)$ \\
& $\mathrm{C}(10)-\mathrm{H}(10 \mathrm{~B}) \cdots \mathrm{O}(1)^{\mathrm{e}}$ & Interlayer & $0 \cdot 052(7)$ & $0 \cdot 759(4)$ \\
& & & & \\
$\gamma$-form & $\mathrm{O}(2)-\mathrm{H}(2 \mathrm{~A}) \cdots \mathrm{O}(1)^{\mathrm{g}}$ & Acid dimer & $0 \cdot 6(1)$ & $1 \cdot 9(2)$ \\
& $\mathrm{C}(5)-\mathrm{H}(5) \cdots \mathrm{O}(2)^{\mathrm{f}}$ & Intralayer & $0 \cdot 03(1)$ & $0 \cdot 648(5)$ \\
& $\mathrm{C}(4)-\mathrm{H}(4) \cdots \mathrm{O}(1)^{\mathrm{i}}$ & Interlayer & $0 \cdot 011(8)$ & $0 \cdot 300(4)$ \\
& $\mathrm{C}(10)-\mathrm{H}(10 \mathrm{~B}) \cdots \mathrm{O}(3)^{\mathrm{j}}$ & Interlayer & $0 \cdot 016(7)$ & $0 \cdot 319(4)$ \\
$\alpha$-dimer & $\mathrm{C}(11)-\mathrm{H}(11 \mathrm{~B}) \cdots \mathrm{O}(1)^{\mathrm{k}}$ & Interlayer & $0 \cdot 017(6)$ & $0 \cdot 277(4)$ \\
& $\mathrm{O}(2)-\mathrm{H}(2 \mathrm{~A}) \cdots \mathrm{O}(1)^{1}$ & Acid dimer & $0 \cdot 18(8)$ & $5 \cdot 31(8)$ \\
& $\mathrm{C}(7)-\mathrm{H}(7) \cdots \mathrm{O}(3)^{\mathrm{m}}$ & Intramolecular & $0 \cdot 034(6)$ & $0 \cdot 576(4)$ \\
& $\mathrm{C}(8)-\mathrm{H}(8) \cdots \mathrm{O}(3)^{\mathrm{n}}$ & Intramolecular & $0 \cdot 07(1)$ & $1 \cdot 146(5)$ \\
& $\mathrm{C}(11)-\mathrm{H}(11 \mathrm{~B}) \cdots \mathrm{O}(1)^{\mathrm{m}}$ & Intramolecular & $0 \cdot 05(1)$ & $0 \cdot 683(7)$ \\
& $\mathrm{C}(4)-\mathrm{H}(4) \cdots \mathrm{O}(2)^{\mathrm{p}}$ & Intermolecular & $0 \cdot 02(1)$ & $0 \cdot 427(5)$ \\
& $\mathrm{C}(11)-\mathrm{H}(11 \mathrm{~A}) \cdots \mathrm{O}(1)^{\mathrm{q}}$ & Intermolecular & $0 \cdot 03(2)$ & $0 \cdot 622(7)$ \\
\hline
\end{tabular}

Symmetry: (a) $-1-x, 2-y,-z$; (b) $-1-x, 3-y,-z$; (c) $x, 1+y, z$; (d) $-x, 2-y, 1-z$; (e) $1+x, y, z$; (f) $-x, 2-y,-z$; (g) $\frac{1}{2}-x, \frac{5}{2}+y, \frac{1}{2}-z$; (i) $-\frac{1}{2}-x,-\frac{1}{2}+y, z$; (j) $\frac{1}{2}-x,-\frac{1}{2}+y, \frac{1}{2}-y$; (k) $x, y-1, z$; (1) $-1-x,-y, z ;(\mathrm{m})-x,-y,-z ;$ (n) $x, y, z$; (p) $x, \frac{1}{2}-y,-\frac{1}{2}+z$; (q) $x, \frac{1}{2}-y, \frac{1}{2}-z$ 

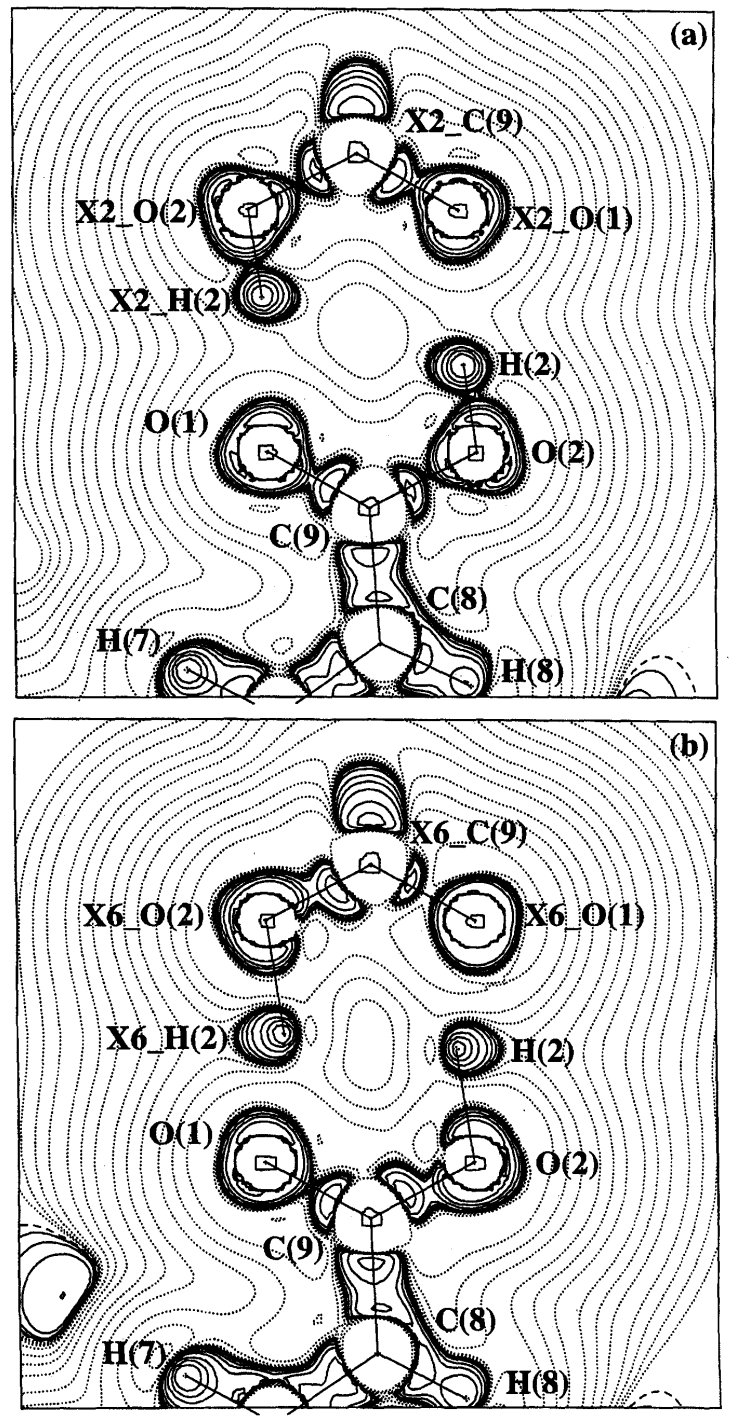

Figure 6. Contour maps of the Laplacian of the total density in the $\mathrm{O}(1), \mathrm{O}(2)$ and $\mathrm{C}(9)$ plane for (a) $\alpha$ - and (b) $\gamma$-forms.

the $\alpha$-form $(-0 \cdot 27,-0 \cdot 28$ and $0 \cdot 19 e)$. The ethoxy oxygen, $\mathrm{O}(3)$, exhibited charges of -0.39 and -0.16 in the $\gamma$ - and $\alpha$-forms respectively. The molecular geometry in the two forms can be rationalized based on the above discussion. If the molecule in the $\gamma$ form were planar, the ethoxy group at the ortho position would pump in more charge through resonance which would simply destabilize the charge separation in the molecule. Thus, it is clear that the ionic nature of the near symmetric hydrogen bond in the $\gamma$-form goes hand in hand with the localization of charge density in the respective bond regions and the non-planarity of the molecule. 


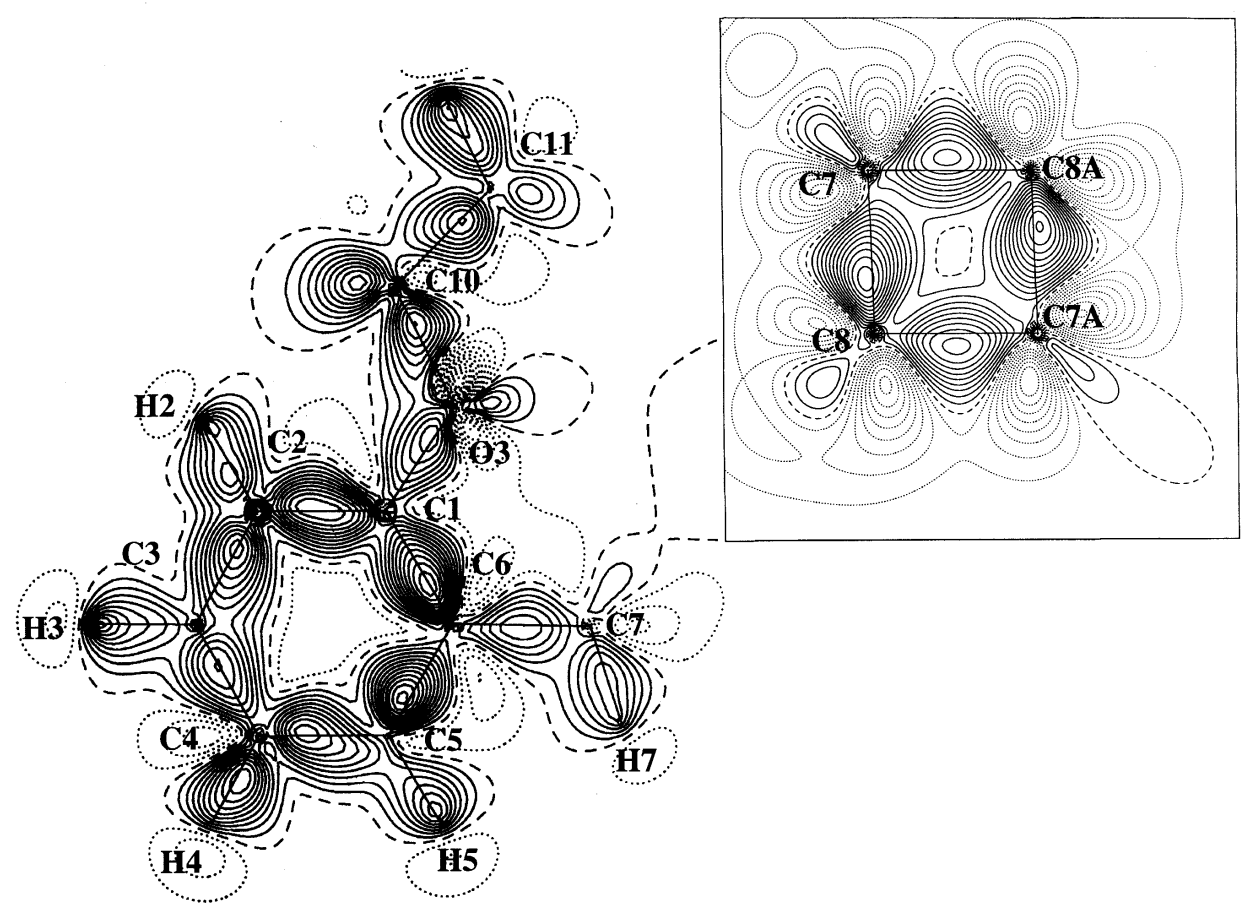

Figure 7. Deformation density map of the photodimer, 2,2'-diethoxy $\alpha$ truxillic acid in the plane of the phenyl ring. The inset shows the deformation density in the plane of the cyclobutane ring. Contour interval $=0.075 e \AA^{-3}$.

We now discuss the nature of charge distribution in the photodimer in comparison with the monomers in the two polymorphs (figure 7). The geometry and the bond properties of the dimer differ significantly not only in the reactive region but also in the other parts of the molecule. The benzene ring, however, remains essentially unaffected upon dimerization. The $\rho_{\mathrm{CP}}$ values of $\mathrm{C}(1)-\mathrm{O}(3)$ and $\mathrm{O}(3)-\mathrm{C}(10)$ bonds are much closer, $2 \cdot 28(8)$ and $2.32(6) e \AA^{-3}$ respectively. The densities in $\mathrm{C}(6)-\mathrm{C}(7)$ and $\mathrm{C}(8)-\mathrm{C}(9)$ regions are typical of single bonds. The bonding within the carboxylic group resembles that in the $\alpha$-form with $\rho_{\mathrm{CP}}$ values of 3.55(9), 2.83(9) and $2 \cdot 6(2) e \AA^{-3}$ for $\mathrm{C}(9)=\mathrm{O}(1), \mathrm{C}(9)-\mathrm{O}(2)$ and $\mathrm{O}(2)-\mathrm{H}(2 \mathrm{~A})$ respectively. The intermolecular $\mathrm{O}(2)-\mathrm{H}(2 \mathrm{~A}) \cdots \mathrm{O}(1)$ bond carries a small density of $\sim 0 \cdot 18(8) e \AA^{-3}$ with a Laplacian of $\sim 5.31(8) e \AA^{-5}$ as in the $\alpha$-form. The $\mathrm{C}-\mathrm{H} \cdots \mathrm{O}$ contacts exhibit low densities (mean value $0.04 e \AA^{-3}$ ) and small Laplacians as listed in table 5. The cyclobutane ring resulting from the photodimerization of the $\alpha$-form is shown in the inset of figure 7. The ring exhibits a $(3,+1) \mathrm{CP}^{26}$ at the inversion centre with a density of $\sim 0.62 e \AA^{-3}$ and a Laplacian of $\sim 5.8 e \AA^{-5}$. The $\mathrm{C}-\mathrm{C}$ bonds of the cyclobutane ring exhibit low values of $\rho_{\mathrm{CP}}$ and Laplacians $\left(\sim 1.58 e \AA^{-3}\right.$ and $\sim$ $11.2 e \AA^{-5}$ respectively), implying that the bonds are weak. The contours in the $\mathrm{C}(7)-$ $\mathrm{C}(8)$ and $\mathrm{C}(7 \mathrm{~A})-\mathrm{C}(8 \mathrm{~A})$ regions lie outside the interatomic vector. These are bent bonds characteristic of strained rings ${ }^{27,28}$. Ellipticity values of the $C(7)-C(8)$ and $\mathrm{C}(7)-\mathrm{C}(8 \mathrm{~A})$ bonds are high $(0 \cdot 13$ and 0.19 respectively) compared to an ideal single 
bond for which ellipticity is zero. The polarization associated with the $\mathrm{C}(7)-\mathrm{C}(8)$ bond is noticeably higher (8\%) compared to the value in $\mathrm{C}(7)-\mathrm{C}(8 \mathrm{~A}) \sim 1 \%$.

\section{Conclusions}

The present study of the reactivity of $o$-ethoxy cinnamic acid has provided some fine details related to the solid state photoreactivity of this compound, involving $(2+2)$ cycloaddition. The molecule in the reactive $\alpha$-form is essentially planar, but in the $\gamma$-form the side groups are out of the plane of the benzene ring. The adjacent cinnamoyl double bonds in the $\alpha$-form face each other at a favourable distance $(\sim 4.514 \AA)$ while in the $\gamma$-form, the double bonds are not only placed at a larger distance $(\sim 5 \cdot 251 \AA)$ but are also not properly oriented with respect to each other. This is due to the significant differences between the structures in the two forms, the most noteworthy one being the presence of near-symmetric $\mathrm{O}-\mathrm{H} \cdots \mathrm{O}$ hydrogen bonds in the $\gamma$-form compared to the ordinary carboxylic dimer contacts in the $\alpha$ form. The nature of the hydrogen bonds is confirmed by IR spectroscopy measurements. The $\mathrm{O}-\mathrm{H}$ stretching frequency at $\sim 3000 \mathrm{~cm}^{-1}$, common to carboxylic acid dimers, is not observed in the spectrum of the $\gamma$-form. Instead, two additional bands appear around $1600 \mathrm{~cm}^{-1}$ due to the symmetric hydrogen bond. The intermolecular $\mathrm{C}-\mathrm{H} \cdots \mathrm{O}$ contacts in the $\gamma$-form are considerably weakened due to the presence of the near-symmetric hydrogen-bonded dimer.

There are also important differences in the charge density distribution between two forms. The molecule being planar in the $\alpha$-form, effects due to conjugation are clearly seen in the charge density. The $\rho_{\mathrm{CP}}$ of the double bond is considerably smaller $\left(2.27 e \AA^{-3}\right)$ compared to that in the $\gamma$-form $\left(2.55 e \AA^{-3}\right)$. The ethoxy link to the phenyl ring carries some extra density due to charge migration from the ethoxy bond. Such effects are not observed in the case of the $\gamma$-form. The symmetric hydrogen bond of the latter being ionic, the molecule prefers non-planar geometry. The cyclobutane ring formed by the dimerization is not exactly a square, the angular distortion being $1 \cdot 8^{\circ}$. New $\mathrm{C}-\mathrm{C}$ bonds are slightly longer compared to the other pair. The ring is strained, all the bonds being associated with small densities and Laplacians.

\section{Acknowledgement}

The authors thank Professor C N R Rao, FRS for suggesting the problem and for useful discussions.

\section{References}

1. Cohen M D, Schmidt G M J and Sonntag F I 1964 J. Chem. Soc. 2000

2. Enkelmann V, Wegner G, Novak K and Wagener K B 1993 J. Am. Chem. Soc. 115 10390

3. Jeffrey G A and Piniella J F (eds) 1991 The application of charge density research to chemistry and drug design (New York: Plenum)

4. Ortmann I, Werner St and Kruger C 1992 J. Am. Chem. Soc. 1145048

5. Madsen D, Flensburg C and Larsen S 1998 J. Phys. Chem. A102 2177

6. Kulkarni G U, Kumardhas P and Rao C N R 1998 Chem. Mater. 103498

7. Furniss B S, Hannaford A S, Smith P W G and Tatchell A R (eds) 1989 Vogel's textbook of practical organic chemistry (Harlow, Essex: Addison Wesley-Longman) 
8. Siemens Analytical X-ray Instruments Inc. 1995 Madison, Wisconsin, USA

9. SHELXTL 1995 (Silicon Graphics version) Siemens Analytical X-ray Instruments Inc. Madison, Wisconsin, USA

10. Allen F H, Kennard O, Watson D G, Brammer L, Orpen A G and Taylor R $1987 \mathrm{~J}$. Chem. Soc., Perkin Trans. II S1

11. Schomaker V and Trueblood K N 1998 Acta Cryst. B54 507

12. Hirshfeld H L 1976 Acta Crystallogr. A32 239

13. Hansen N K and Coppens P 1978 Acta Crystallogr. A34 909

14. Koritsansky T, Howard S T, Richter T, Mallinson P R, Su Z and Hansen N K 1995 XD A computer program package for multipole refinement and analysis of charge densities from diffraction data (Cardiff, Glasgow, Buffalo, Nancy, Berlin); xd-user@chemie.fuberlin.de

15. Cremer D and Kraka E 1984 Croat. Chem. Acta 571259

16. Collard K and Hall G G 1977 Int. J. Quantum Chem. 12623

17. Bader R F W and Essen H 1984 J. Chem. Phys. 801943

18. Naradelli M 1983 Comput. Chem. 795

19. Bellamy L J 1975 The infrared spectra of complex molecules 3rd edn (London: Chapman and Hall)

20. Rao C N R and Ferraro J R 1970 Spectroscopy in inorganic chemistry (New York: Academic Press) vol. 1

21. Braunholtz J T, Hall G E, Mann F G and Sheppard N 1959 J. Chem. Soc. 868

22. Blinc R and Hadzi D 1960 Spectrochem. Acta 16852

23. Coppens P 1994 Annu. Rev. Phys. Chem. 43663

24. Morrison R T and Boyd R N 1989 Organic chemistry 5th edn (New Delhi: Prentice HallIndia)

25. Mallinson P R, Wozniak K, Smith G T and McCormack K L 1997 J. Am. Chem. Soc. 119 11502

26. Bader R F W 1990 Atoms in molecules - A quantum theory (Oxford: Clarendon)

27. Angermund K, Claus K H, Goddard R and Kruger C 1985 Angew. Chem., Intl. Ed. Engl. 24237

28. Irngartinger H and Strack S 1998 J. Am. Chem. Soc. 1205818 